\title{
Magneto-thermal convection of low concentration nanofluids
}

\author{
Aleksandra Roszko ${ }^{1}$, Elzbieta Fornalik-Wajs ${ }^{1}$, Janusz Donizak $^{1}$, Jan Wajs ${ }^{2}$, Anna Kraszewska ${ }^{1}$, Lukasz Pleskacz ${ }^{1}$, \\ and Sasa Kenjeres ${ }^{3}$ \\ ${ }^{1}$ AGH University of Science and Technology, Department of Fundamental Research in Energy Engineering, Poland \\ ${ }^{2}$ Gdansk University of Technology, Department of Energy and Industrial Apparatus, Poland \\ ${ }^{3}$ Delft University of Technology, Department of Chemical Engineering, The Netherlands
}

\begin{abstract}
The main aim of this paper was to analyze possible utilization of the low concentration nanofluids and the magnetic field to enhance heat transfer. The studied fluids were based on water with an addition of copper particles (40-60 nm diameter). They belonged to the diamagnetic group of materials. As a first attempt to stated target the analysis of enclosure placed in the maximal value of square magnetic induction gradient was carried out. The maximum was in the centre of investigated cavity and it caused the most complex system of gravitational and magnetic buoyancy forces. In the lower part of cavity both forces acted in the same direction, while in the upper part they counteracted. Therefore an enhancement and attenuation of heat transfer could be observed. Due to the particle concentration and magnetic field action the character of flow was changed. In the case of $50 \mathrm{ppm}$ nanofluid the flow was steady end the strong magnetic field didn't change much in its structure except for the suppression of some vortices. In the case of $500 \mathrm{ppm}$ nanofluid the flow was not steady even without magnetic field, but increasing magnetic induction caused change of its structure towards the inertial-convective regime of turbulent flow.
\end{abstract}

\section{Introduction}

Due to a technical development, the energy consumption increases. A lot of efforts are put on the better energy utilization and higher efficiency of devices. At the same time the researchers are struggling with the challenges related to the high heat flux transfer in the devices' cooling processes. The most important limitation in obtaining high heat flux transfer by the fluids is their relatively low thermal conductivity [1]. Therefore, there are trials to obtain higher heat transfer by various methods. In this paper a combination of two methods will be taken into account - the application of magnetic field to intensify heat transfer and the addition of copper nanoparticles to base fluid (changing the properties of suspension), which is called nanofluid.

In general, the nanofluids are the mixtures of base fluid and dispersed particles, which sizes do not exceed $100 \mathrm{~nm}$. As a base fluid very often the water and ethylene glycol are used [2]. The variety of particles, their kind, size and shape is very wide [3]. The particles used for suspension production belong to a group of ceramics, carbon based, metals and alloys [3]. From the heat transfer point of view particularly interesting are two last groups of particles with the emphasis placed on the pure metallic particles. In the literature it was mentioned, that the suspension thermal conductivity even with pretty low particles concentration is much higher than in the case of only base fluid [4]. Numerous experimental studies were carried out in the field of superior thermal properties of the nanofluids compared to typical working fluids used in the heat exchangers. Taking into account that the most important parameter responsible for enhanced heat transfer is thermal conductivity, many studies connected with this problem were conducted. Researchers observed enhancement of thermal conductivity in comparison with conventional coolants [5]. A lot of experimental investigations concerned the thermal properties of nanofluids containing nano-particles of alumina $\left(\mathrm{Al}_{2} \mathrm{O}_{3}\right)$ and copper $(\mathrm{CuO})$ oxides. The results demonstrated that adding the nano-particles to the base fluid led to an enhancement of heat transfer. The $60 \%$ improvement of the thermal conductivity was obtained, in comparison with the corresponding base fluids, for only $5 \mathrm{vol} \%$ of the nanoparticles. Also, comparison with various data indicated that the decrease in particles size resulted in increase of thermal conductivity of nanofluid. Effective thermal conductivity raised by $12 \%$ at 3 vol. $\%$ of nanoparticles [4].

In [6] the review of experimental data concerning the thermal conductivity of nanofluids was presented. Many research results were analyzed and compared with each other. The major conclusion from above survey is that the results for similar nanofluids differed from one another

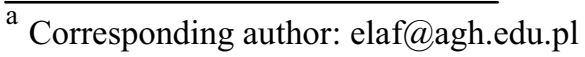


and the reason for that may be the use of various theoretical conductivity models that were applied in calculations.

Several studies on the convective heat transfer of nanofluids have been published in recent years. Khanafer et al. [7] studied the buoyancy-driven heat transfer enhancement of $\mathrm{Cu}$-based nanofluid with various concentrations of suspended particles. Hwang et al. [8] investigated Rayleigh-Benard convection of nanofluids in a rectangular cavity. They applied empirical formulas to evaluate the heat transfer coefficient and reported contrary nanoparticles' effect on heat transfer. Santra et al. [9] studied heat transfer enhancement in differentially heated square cavity. They addressed $\mathrm{Cu}$-water fluid as non-Newtonian and observed a decrease of heat transfer by enlargement of nanoparticles' volume fraction.

Because research concerning the heat transfer of nanofluids have been conducted relatively recent, since early nineties, there are a lot of inconsistencies and unclear mechanisms, which require further studies.

The report by Schwab et al. [10] appears to be the first one to have shown the enhancement of heat transfer by magnetic field in weakly magnetic (paramagnetic or diamagnetic), one-phase fluid. They studied the Rayleigh-Benard convection of the aqueous solution of gadolinium nitrate and reported the Nusselt number versus the temperature difference. Their data distributed either above or below the reference heat transfer rate for a non-magnetic field, i.e., in a terrestrial gravitational state. They placed the experimental enclosure at the location either to enhance or suppress the gravitational acceleration. Furthermore, they proposed a magnetic Rayleigh number using actual gravitational and magnetic acceleration summation.

Tagawa et al. [11] employed the Boussinesq approximation for magnetic force and derived the simple model for the momentum equation and gave numerical analyses for convection of air in an enclosure with a magnetic force. They studied various cases subsequently [12]. The magnetic convection, from the engineering point of view, was presented in a book by Ozoe [13], while Fornalik-Wajs [14] derived theoretical and experimental analysis of paramagnetic fluid magnetic convection. Bednarz et al. [16] and Filar et al. [17] conducted very interesting experimental analysis and obtained results showing intensification of the heat transfer processes in the cubical and thermosyphon-like geometry, respectively. Wrobel et al. [18] published results of experimental and numerical analysis considering a thermo-magnetic convective flow of paramagnetic fluid in an annular enclosure with a round rod core and a cylindrical outer wall. They presented the effect of the magnetic field on the convection of the paramagnetic fluid in the annular vessel in various positions. Kenjeres et al. [19] performed experimental and numerical studies of combined effects of thermal buoyancy and magnetization force applied on a cubical enclosure of paramagnetic fluid heated from below and cooled from top. The magnetization force produced significant changes in flow, enhancement in wall-heat transfer and numerical simulations provided a detailed insights into changes of the local wall-heat transfer and flow structure. Stability diagram, containing three characteristic states: steady, oscillatory and turbulent regimes, was presented.

It was already shown that magnetic field is able to control flow of weakly magnetic substances as the paramagnetics and diamagnetics. In recent years only the numerical studies about applying the external magnetic field to the nanofluids appeared. Examined fluids contained various concentrations of the nanoparticles (usually above $1 \%$ vol.) with different kinds of particles [20] in diverse shapes of experimental enclosures (e.g.): cubical [21], u-shaped [22] and 1-shaped [23]. No papers concerning the experimental studies of nanofluids in the external magnetic field were found.

In the present paper the first step of analysis verifying the potential heat transfer enhancement in the nanofluids by the magnetic field is presented.

\section{Experimental stand}

\subsection{Experimental apparatus}

The experimental setup is presented in Figure 1. It consisted of an experimental enclosure placed in the bore of a superconducting magnet, a heater control system, a constant temperature bath and a data acquisition system connected to a personal computer. The experimental enclosure is shown schematically in Figure 2. The Plexiglas cubical enclosure of size equal to 0.032 [m] was heated (with constant heat flux) from one horizontal wall and isothermally cooled from the opposite one, while the four remaining walls were insulated. A rubber-coated nichrome wire was used as a heater and connected to a DC power supply. The heating power was monitored with multimeters. Water was pumped from a thermostatic water bath through a small cooling chamber built in the cooling wall. The temperature of heated and cooled walls was measured with six T-type thermocouples (three in each wall). The temperature was also measured inside the cube - six K-type thermocouples were inserted and arranged as it is shown in Figure 2. The thermocouples' signals were stored in a computer through a data acquisition system. The enclosure was filled with working fluid.

The enclosure position in the magnet test section was correlated with the location of maximal value of $\operatorname{grad} B^{2}$, where $B$ indicates the magnetic induction. This maximum was in the central part of experimental cavity, in the distance of $0.1[\mathrm{~m}]$ from the magnet top. Such enclosure position in the magnetic field caused complex system of gravitational and magnetic buoyancy forces. In the lower (heated) part of cavity both forces were acting in the same direction, enhancing each other. In the upper (cooled) part forces counteracted, attenuating each other. The detail analysis and understanding will come from the numerical analysis as a next step of presented work. 


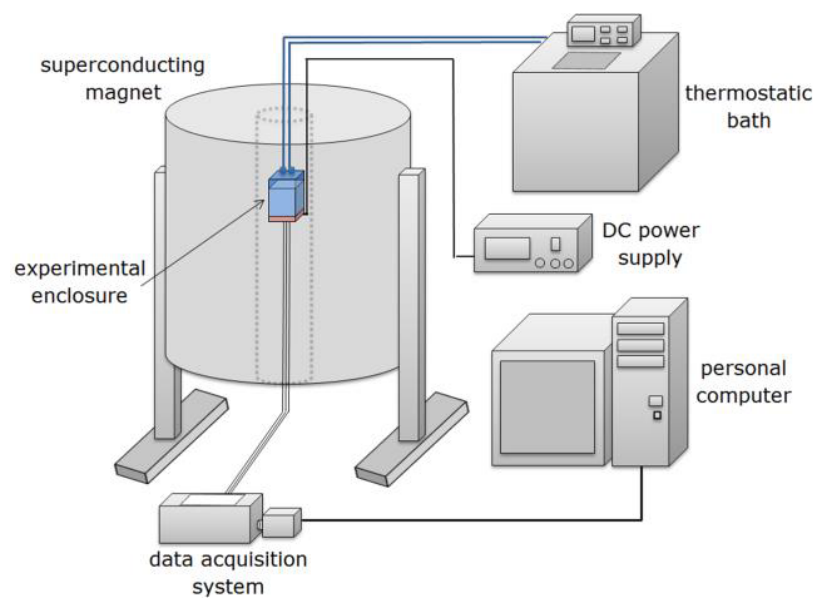

Figure 1. Experimental setup.

\subsection{Working fluid}

Two low particles concentration nanofluids were analyzed. Water was the base fluid, while the particles were made of copper. The particles size was in the range of 40-60 [nm]. First fluid's particle concentration was 50 [ppm], while the second one's - 500 [ppm]. Preparation of nanofluids caused a lot of problems, mentioned also in the literature [24]. Among the others there are mainly the agglomeration and sedimentation of particles. The 50 [ppm] concentration fluid was already prepared and it didn't showed those problem, whereas the 500 [ppm] fluid was prepared for the needs of experiment. Mechanical stirrer was used to mix the base fluid and particles. The process lasted 8 hours and from the transparent fluid the opaque one was obtained. In the next parts of paper the following abbreviations will be applied to indicate the fluids: Cu50 - fluid of 50 [ppm] particles concentration, $\mathrm{Cu} 500$ - fluid of 500 [ppm] particles concentration.

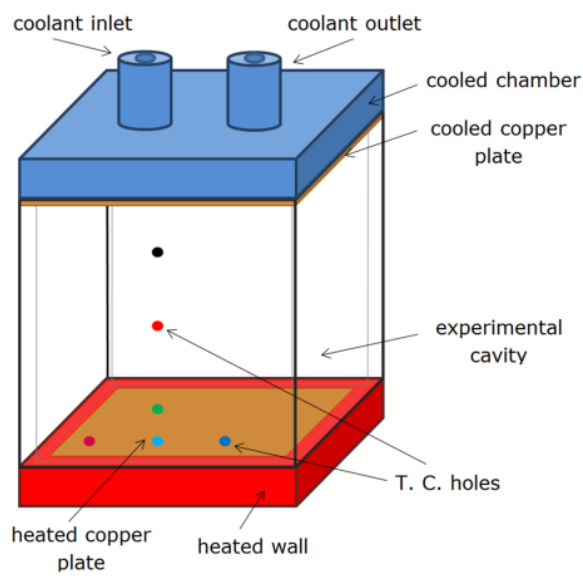

Figure 2. Experimental enclosure.

Following properties necessary for the analysis were measured: magnetic susceptibility, density, viscosity, thermal expansion coefficient. However in the case of Cu50 measured properties didn't show any differences (within the accuracy range of applied devices) in comparison with the water properties. Therefore for this fluid in Table 1 the presented property values are taken as for water.

Table 1. Thermo-physical properties of working fluids. * indicates values taken as or water, ** - values calculated from Eqs., ${ }^{* * *}$ values measured

\begin{tabular}{|c|c|c|c|}
\hline Property & Unit & $\begin{array}{c}\mathrm{Cu} 50 \\
(50 \mathrm{ppm})^{*}\end{array}$ & $\begin{array}{c}\mathrm{Cu} 500 \\
(500 \mathrm{ppm})^{* *}\end{array}$ \\
\hline $\begin{array}{l}\text { Thermal } \\
\text { conductivity }\end{array}$ & $\begin{array}{c}k_{n f} \\
{\left[\mathrm{~W} \cdot(\mathrm{mK})^{-1}\right]}\end{array}$ & 0.617 & 0.714 \\
\hline Density & $\rho_{n f}\left[\mathrm{~kg} \cdot \mathrm{m}^{-3}\right]$ & 995.2 & 1391.4 \\
\hline Specific heat & $\begin{array}{c}c_{p n f} \\
{\left[\mathrm{~J} \cdot(\mathrm{kg} \cdot \mathrm{K})^{-1}\right]}\end{array}$ & 4177 & 3987.2. \\
\hline $\begin{array}{l}\text { Thermal } \\
\text { expans. coef. }\end{array}$ & $\beta_{n f}\left[\mathrm{~K}^{-1}\right]$ & $18 \cdot 10^{-5}$ & $17.4 \cdot 10^{-5}$ \\
\hline $\begin{array}{l}\text { Dynamic } \\
\text { viscosity }\end{array}$ & $\begin{array}{c}\mu_{n f} \\
{\left[\mathrm{~kg} \cdot(\mathrm{m} \cdot \mathrm{s})^{-1}\right]}\end{array}$ & $8.31 \cdot 10^{-4}$ & $9.4 \cdot 10^{-4}$ \\
\hline $\begin{array}{l}\text { Electrical } \\
\text { conductivity }\end{array}$ & $\begin{array}{c}\sigma_{n f} \\
{\left[\mathrm{~S} \cdot \mathrm{m}^{-1}\right]}\end{array}$ & $5.58 \cdot 10^{-6}$ & $6.37 \cdot 10^{-6}$ \\
\hline $\begin{array}{l}\text { Mass magn. } \\
\text { susceptibility }\end{array}$ & $\stackrel{\chi_{m}}{\left[\mathrm{~m}^{3} \cdot \mathrm{kg}^{-1}\right]}$ & $-9.051 \cdot 10^{-9}$ & $-10.1 \cdot 10^{-9} * * *$ \\
\hline
\end{tabular}

The measurements of thermophysical properties (except the magnetic susceptibility) of Cu500 were very difficult due to the sedimentation of particles. The values were changing with time as the particle were settling. Therefore these measurements were taken as erroneous. For the heat transfer analysis the formulas listed in Table 2 were taken to calculate properties of $\mathrm{Cu} 500$. The following subscripts are applied to indicate the components: $b f$ - base fluid, $p$ - particles and $n f-$ nanofluid. Symbol $\phi$ represents the volume percentage of particles.

Table 2. Formulas applied for the calculation of Cu500 thermophysical properties [25]

\begin{tabular}{|c|c|}
\hline Property & Formula, source \\
\hline $\begin{array}{c}\text { Thermal } \\
\text { conductivity }\end{array}$ & $k_{n f}=k_{b f} \frac{k_{p}+2 k_{b f}+2 \phi\left(k_{p}-k_{b f}\right)}{k_{p}+2 k_{b f}-\phi\left(k_{p}-k_{b f}\right)}$ \\
\hline $\begin{array}{c}\text { Density and } \\
\text { Specific heat } \\
\text { product }\end{array}$ & $\rho c_{p_{n f}}=\phi\left(\rho c_{p}\right)_{p}+(1-\phi)\left(\rho c_{p}\right)_{f}$ \\
\hline $\begin{array}{c}\text { Thermal } \\
\text { expans. coef. }\end{array}$ & $\beta_{n f}=\phi \beta_{p}+(1-\phi) \beta_{f}$ \\
\hline $\begin{array}{c}\text { Dynamic } \\
\text { viscosity }\end{array}$ & $\mu_{n f}=\frac{\mu_{f}}{(1-\phi)^{2.5}}$ \\
\hline $\begin{array}{c}\text { Electrical } \\
\text { conductivity }\end{array}$ & $\mu_{n f}=\left[1+\frac{\mu_{f}(1-2.5 \phi) \phi<0.05}{\left(\frac{\sigma_{p}}{\sigma_{f}}-1\right) \phi}\right.$ \\
\hline
\end{tabular}


The base fluid - water was diamagnetic, the same as the copper particles. Obtained nanofluids were then also diamagnetic. Due to the low electrical conductivity they were considered as electrically non-conductive. It meant that the Lorentz force in this system could be neglected [26]. The only forces governing the fluid flow were: the gravitational buoyancy and magnetic buoyancy forces.

\section{Experimental procedure}

For both analyzed nanofluids the procedure was the same. First step was connected with the analysis of conduction state, therefore the enclosure was placed in such configuration that the heated plate was at the top, while the cooled one at the bottom. The enclosure was located in the magnet working section to keep the same temperature of environment (about $18\left[{ }^{\circ} \mathrm{C}\right]$ ). The analysis of conduction state was necessary for determination of the Nusselt number. The way of Nusselt number calculation will be described in section 4.1.

The next step was connected with analysis of thermomagnetic convection. At first the natural convection of nanofluids was analyzed. The power supply was set to obtain chosen temperature difference between heated and cooled walls about $\Delta T \sim 3.5\left[{ }^{\circ} \mathrm{C}\right]$ (the value came from the preliminary measurements and the calibration of setup). The enclosure was then left to obtain the stable state. It lasted about 2 [h]. After this time the controlled parameters (temperature, electrical current, voltage) were recorded and the magnetic field was applied to the system. The value of magnetic induction was changed by stages of $1[\mathrm{~T}]$ up to 10 [T]. At each stage the system had to reach the steady state before recording the analyzed signals output. The time needed to obtain the steady state slightly varied for each case (depending on the flow mode) but it was always in the range of 1-2 [h].

\section{Signal analysis}

Recorded temperature time series enabled investigations of two aspects of thermo-magnetic convection: the heat transfer and flow structure. The heat transfer was determined through calculation of the Nusselt number, while the flow structure trough the Fast Fourier Transform (FFT) and spectral analysis.

\subsection{Heat transfer}

The Nusselt number definition based on the convection and conduction heat fluxes can be written as:

$$
\mathrm{Nu}=\frac{\dot{Q}_{\text {net_conv }}}{\dot{Q}_{\text {net_cond }}} .
$$

Estimation of the net convection $\left(Q_{\text {net_conv }}\right)$ and net conduction ( $\dot{Q}_{\text {net_cond }}$ ) heat fluxes was done according to a method invented by Ozoe and Churchill [27] and based on the following equations:

$$
\dot{Q}_{\text {net_conv }}=\dot{Q}_{\text {conv }}-\dot{Q}_{\text {loss }},
$$

It was assumed that the heat loss depends strictly on the temperature of the heated wall and does not depend on the heat transfer mode inside the enclosure.

As a first step in the Nusselt number estimation the conduction experiment was done. The $\dot{Q}_{\text {loss }}$ was estimated from the following equation:

$$
\dot{Q}_{\text {loss }}=\dot{Q}_{\text {cond }}-\dot{Q}_{\text {theor_cond }} \text {, }
$$

where

$$
\dot{Q}_{\text {theor_cond }}=l k_{n f} \Delta T,
$$

( $l$ indicates the size of enclosure equal to $0.032[\mathrm{~m}], k_{n f}$ is the thermal conductivity of nanofluid and $\Delta T$ is the temperature difference between heated and cooled plate) $\dot{Q}_{\text {theor_cond }}$ was calculated from Fourier's law for the conduction area of $l^{2}$. The estimated heat loss was linearly approximated and the equations for both fluids are presented below

$$
\begin{aligned}
Q_{\text {loss_Cu } 50} & =0.069 \cdot \Delta T, \\
Q_{\text {loss_Cu } 500} & =0.0856 \cdot \Delta T .
\end{aligned}
$$

There are two different equations, because the heat loss changed due to the higher thermal conductivity of $\mathrm{Cu} 500$. Therefore in the heat transfer analysis each of the fluids was considered separately with an utilization of the characteristic for it equation. Applying equations (2), (3) and (4) to equation (1), the definition for the Nusselt number could be rewritten

$$
\mathrm{Nu}=\frac{Q_{\text {conv }}-\dot{Q}_{\text {loss }}}{l k_{n f} \Delta T}
$$

The convection heat flux $\left(\dot{Q}_{\text {conv }}\right)$ was calculated as a product of the electrical current and voltage of heater supply. Having the convection heat flux $\left(\dot{Q}_{\text {conv }}\right)$, the heat loss ( $\dot{Q}_{\text {loss }}$ ) estimated from equations (3) and theoretical conduction heat flux ( $\dot{Q}_{\text {theor cond }}$ ) it was possible to estimate the Nusselt number. The results are presented in Figure 3.

\subsection{Flow structure}

The spectral analysis of scalar field (for example temperature or concentration) are useful in the analysis of turbulent transport mechanisms. Assuming that the turbulence is homogeneous, the spectral functions can be calculated with utilization of FFT. In the presented analysis the temperature signals not the temperature fluctuations were considered.

In dependence on the flow the frequency spectra can present various character. For the steady convective flow in closed cavity they can represent number of vertical structures rotating with particular frequencies. The frequency spectra may show then the characteristic sharp peaks, which can be related with periodic coherent structures [28]. The smaller frequency is indicated the larger vortical structure appears. In the case of turbulent flow the vortices are continuously changing from the large to the smallest ones. This is only the qualitative not quantitative information, however it can help to describe the flow structure. 
There is an analogy between the spectral analysis of scalar parameter and the Kolmogorov energy spectrum $[28,29]$. The FFT analysis was conducted with an algorithm [30].

The spectral functions of temperature generally depends on the energy dissipation, temperature, kinematic viscosity and thermal diffusivity. In some range, the spectral function does not depend on the diffusion processes, therefore do not depend on the kinematic viscosity or thermal diffusivity. This range is called inertial-convective and the spectral function is similar to the energy spectrum as the power function of wave number with exponent $-5 / 3$ [28]. When the thermal diffusivity becomes more significant, then the spectral function is proportional to the inverse value of wave number $\left(k^{-1}\right)$ [28]. This turbulent range is called viscousdiffusive [29]. Both of the functions are marked in Figures 4 and 5 as the straight lines with slopes of $-5 / 3$ and -1 .

\section{Results and discussion}

The results of heat transfer analysis are presented in Figure 3. The Nusselt number as a function of the thermo-magnetic Rayleigh number is shown in Figure 3(a). The thermo-magnetic Rayleigh number is defined as:

$$
\operatorname{Ra}_{\mathrm{TM}}=\operatorname{Ra}_{\mathrm{T}}\left[1-\gamma B_{z}\left(\frac{\partial B_{z}}{\partial z}\right)\right],
$$

where $\mathrm{Ra}_{\mathrm{T}}$ is the thermal Rayleigh number described by the following formula

$$
\mathrm{Ra}_{\mathrm{T}}=\frac{g \beta_{n f} \rho_{n f}^{2} c_{p n f}}{\mu k_{n f}} l^{3} \Delta T,
$$

while $\gamma$ is the magnetization number written as:

$$
\gamma=\frac{\chi_{m} B_{\max }^{2}}{\mu_{m} g d}
$$

and $g$ - gravitational acceleration; $\beta_{n f}-$ thermal expansion coefficient; $\rho_{n f}-$ density; $c_{p n f}-$ specific heat; $\mu_{n f}-$ dynamic viscosity; $k_{n f}-$ thermal conductivity; $l$ characteristic dimension; $\Delta T$ - temperature difference; $\chi_{m}$ - mass magnetic susceptibility; $B_{\max }$ - magnetic induction in the central part of coil; $B_{\mathrm{z}}$ - magnetic induction in the position of enclosure centre; $\mu_{m}$ - vacuum magnetic permeability. The value of $B_{z}$ and $\operatorname{grad} B_{z}$ were calculated numerically based on the superconducting magnet coil technical data [31] and led to the relations:

$$
\begin{aligned}
B_{z} & =0,6265 \cdot B_{\max }, \\
\frac{\partial B_{z}}{\partial z} & =-5,8742 \cdot B_{\max } .
\end{aligned}
$$

The negative sign of thermo-magnetic Rayleigh number was coming from the relation between the natural and magnetic convection in accordance to Eq. (8) and suggested prevalence of "magnetic part" of this definition. At $0 \mathrm{~T}$ of magnetic induction the Nusselt number got higher values for $\mathrm{Cu} 50$, so for the fluid of lower particles concentration. It could be explained with the Nusselt number definition (Eqs. (1) and (7)). Increasing thermal conductivity (as for $\mathrm{Cu} 500$ ) caused increase of the conduction heat flux and decrease of the (a)

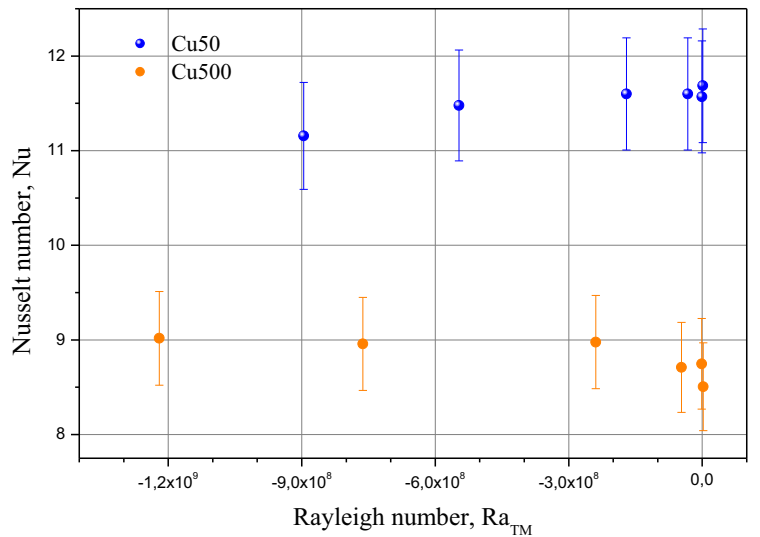

(b)

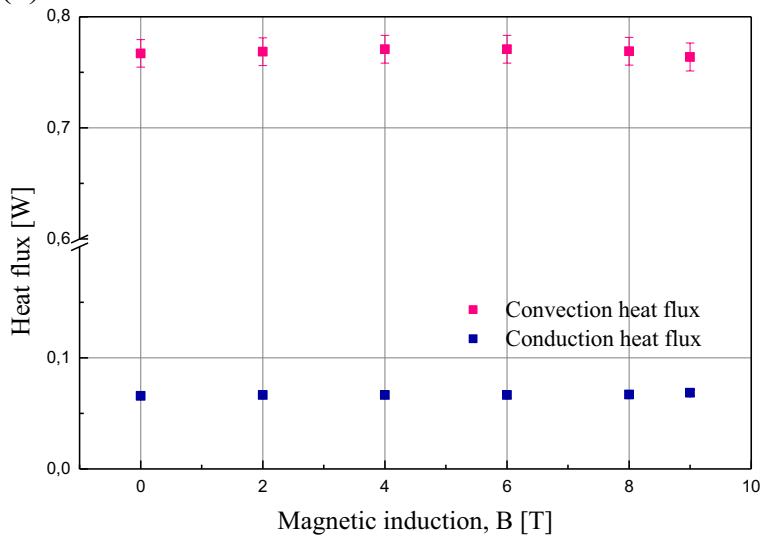

(c)

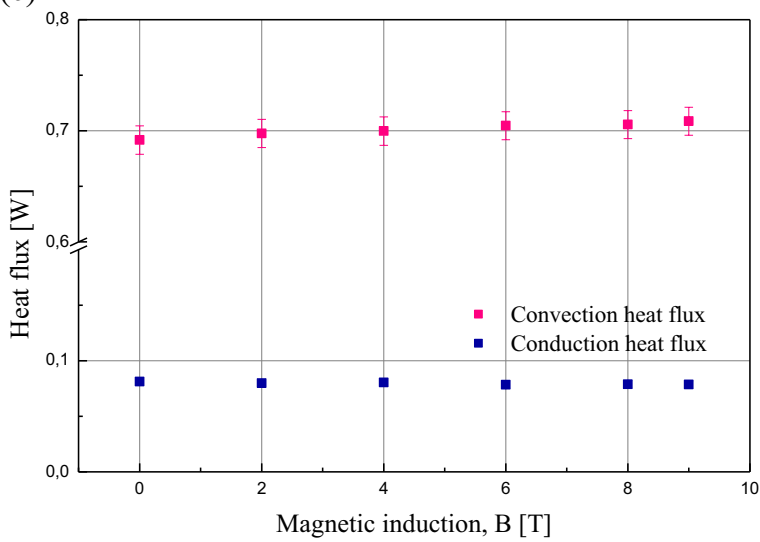

Figure 3.(a) the Nusselt number versus the magnetic Rayleigh number, (b) the convection and conduction heat fluxes versus the magnetic induction for $\mathrm{Cu} 50$; (c) the convection and conduction heat fluxes versus the magnetic induction for $\mathrm{Cu} 500$

Nusselt number, when the other conditions were kept the same. Analysis of system under the magnetic field should be done separately for each fluid. Application of the magnetic field to the system with $\mathrm{Cu} 50$ changed slightly the situation, at magnetic induction of $2[\mathrm{~T}]\left(\mathrm{Ra}_{\mathrm{TM}}=\right.$ $\left.-7 \cdot 10^{5}\right)$ increase of the Nusselt number could be observed. Further increase of magnetic induction up to 9 [T] caused continuous decrease of the Nusselt number. In the case of $\mathrm{Cu} 500$ at $2[\mathrm{~T}]$ of magnetic induction $\left(\mathrm{Ra}_{\mathrm{TM}}=-9.9 \cdot 10^{5}\right)$, there is no measurable change in the Nusselt number, but at $4[\mathrm{~T}]$ of magnetic induction $\left(\mathrm{Ra}_{\mathrm{TM}}=-4.7 \cdot 10^{7}\right)$ small increase of its value could be found. 
(a)

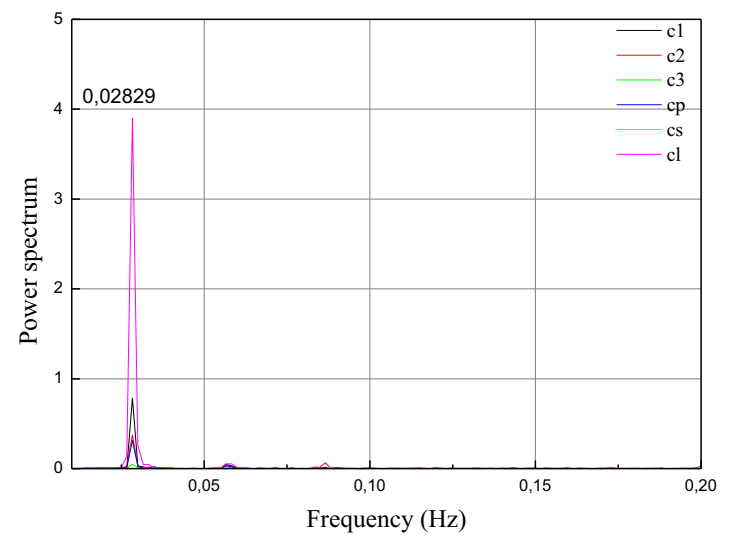

(c)

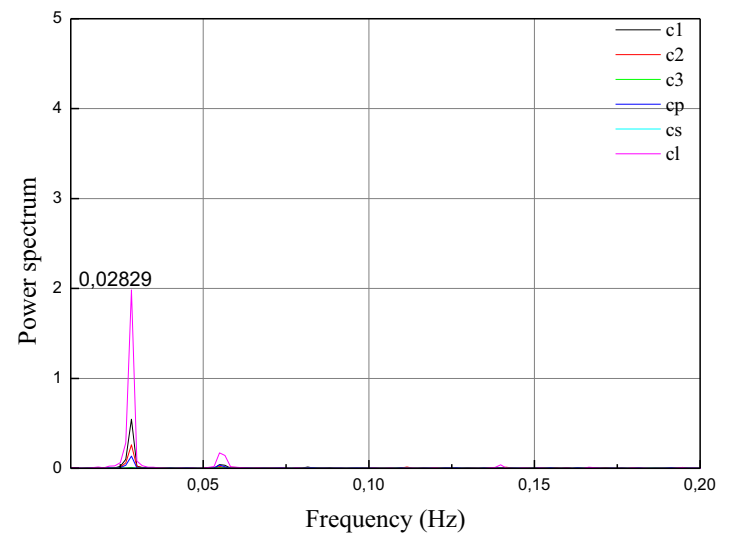

(e)

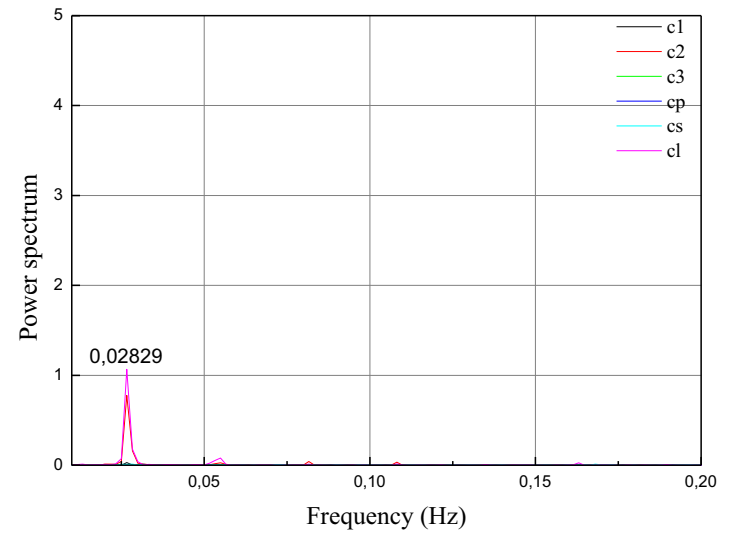

(b)

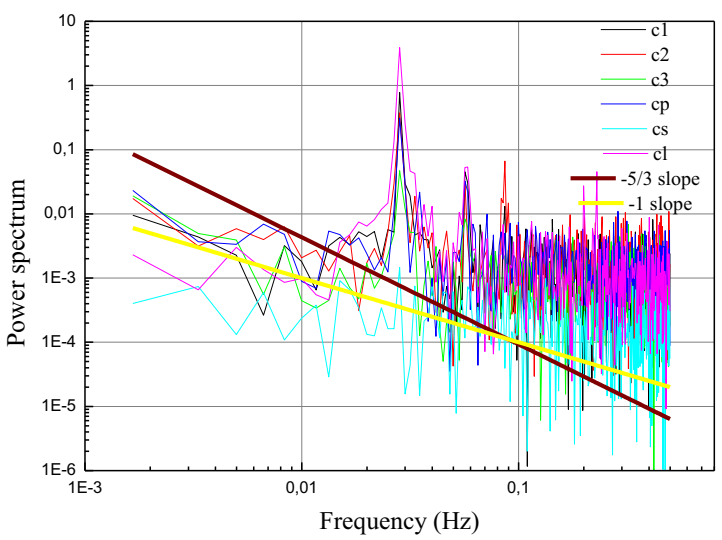

(d)

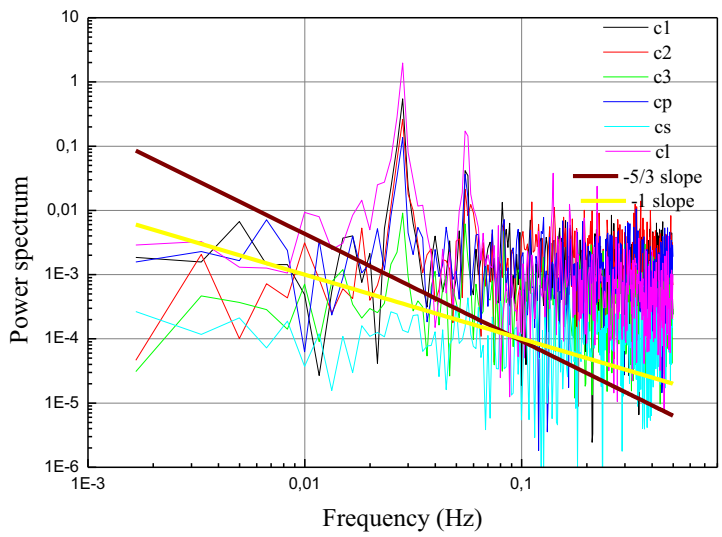

(f)

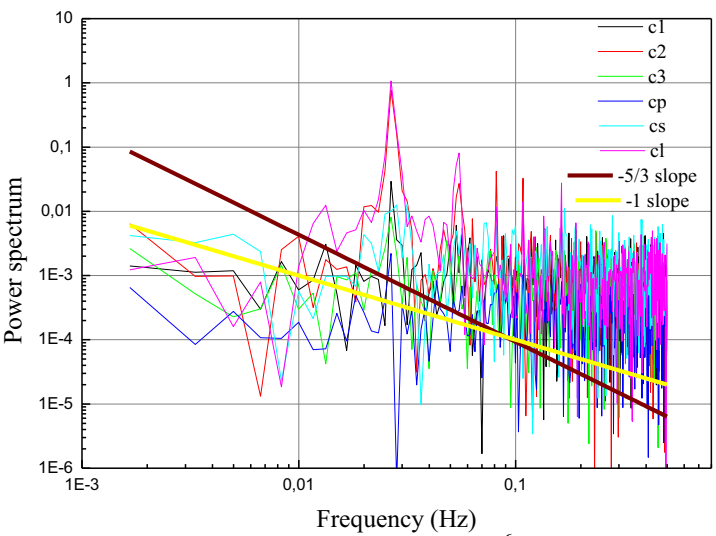

Figure 4. The power spectrum versus frequency for $\mathrm{Cu} 50$ (a) at $0[\mathrm{~T}]$ of magnetic induction, $\mathrm{Ra}_{\mathrm{TM}}=1.41 \cdot 10^{6}$, (b) $\log$-log scale at 0 [T] of magnetic induction, $\mathrm{Ra}_{\mathrm{TM}}=1.41 \cdot 10^{6}$, (c) at 6 [T] of magnetic induction, $\mathrm{Ra}_{\mathrm{TM}}=-1.71 \cdot 10^{8}$, (b) $\log$ - $\log$ scale at 6 [T] of magnetic induction, $\mathrm{Ra}_{\mathrm{TM}}=-1.71 \cdot 10^{8}$, (c) at 8 [T] of magnetic induction, $\mathrm{Ra}_{\mathrm{TM}}=-5.46 \cdot 10^{8}$, (b) $\log -\log$ scale at 8 [T] of magnetic induction, $\mathrm{Ra}_{\mathrm{TM}}=-5.46 \cdot 10^{8}$.

Further increase of magnetic induction resulted in increase of the Nusselt number. It should be emphasized that the boundary conditions were the same only the concentration of fluids was different. Increase of the $\mathrm{Cu} 500$ thermal conductivity influenced the temperature field and indirectly the forces acting on the fluid and then the heat transfer. As it was mentioned, the force system in the analysed enclosure was complex, that is why the tendency of Nusselt number changes was different for each fluid.

In Figures 3(b) and 3(c) comparison between the convective and conduction heat fluxes for $\mathrm{Cu} 50$ and $\mathrm{Cu} 500$ (respectively) are presented. In both cases the convection heat flux was higher than the conduction one. For $\mathrm{Cu} 50$ the convection heat flux was higher than for $\mathrm{Cu} 500$, what was also represented by higher value of the Nusselt number (Figure 3(a)). However, the conduction heat flux was higher for Cu500 of about $20 \%$.

The results of spectral analysis are presented in Figures 4 and 5. The analysis was carried out for all recorded signals from all thermocouples placed inside the enclosure. Figure 4 shows the thermal power spectrum versus the frequency for $\mathrm{Cu} 50$ in dependence on the magnetic induction. In Figure 4(a) the magnetic induction was equal to $0 \mathrm{~T}$ (natural convection without magnetic field), in Figure 4(c) $-6 \mathrm{~T}$ and in Figure 4(e) $-8 \mathrm{~T}$. 
(a)

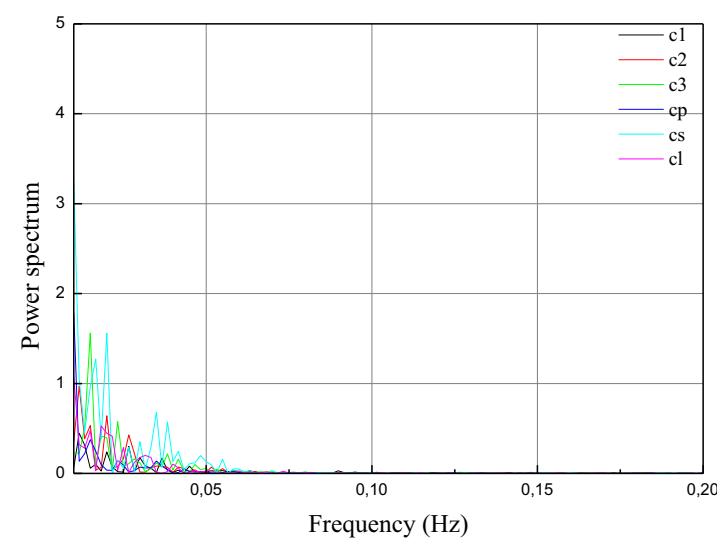

(c)

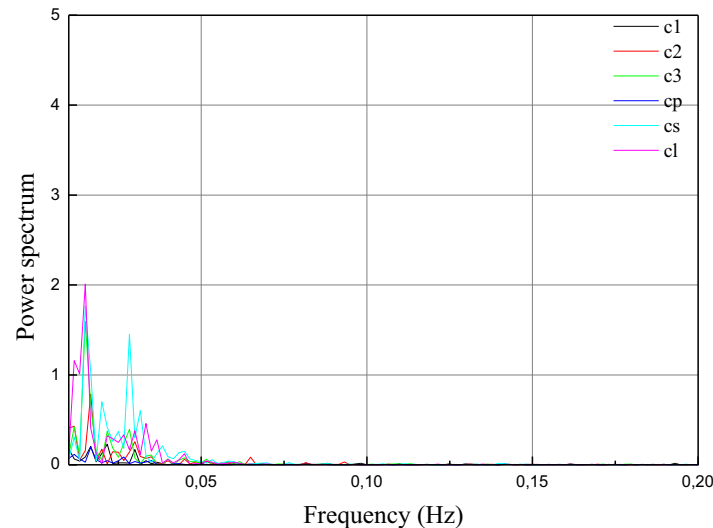

(e)

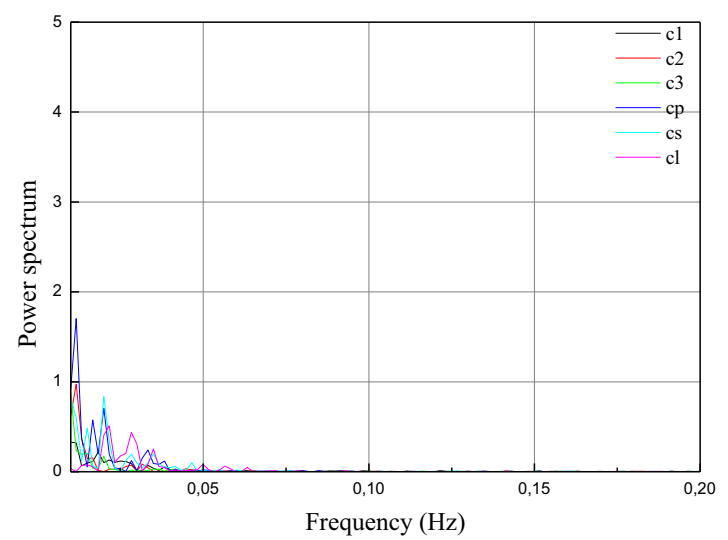

(b)

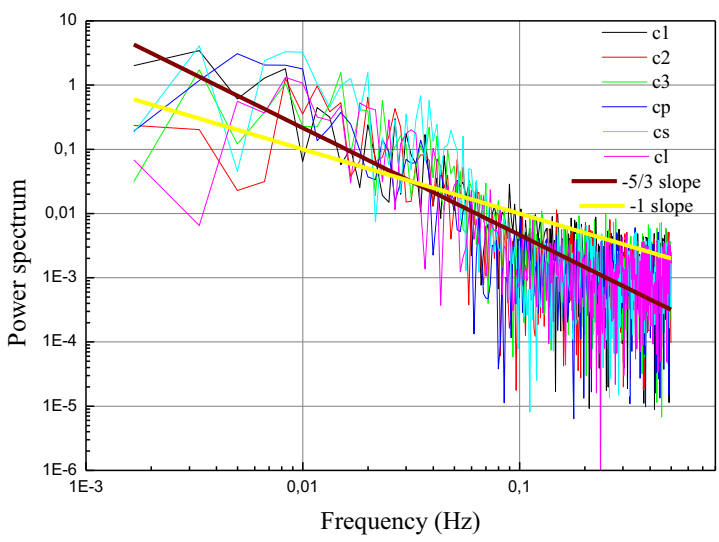

(d)

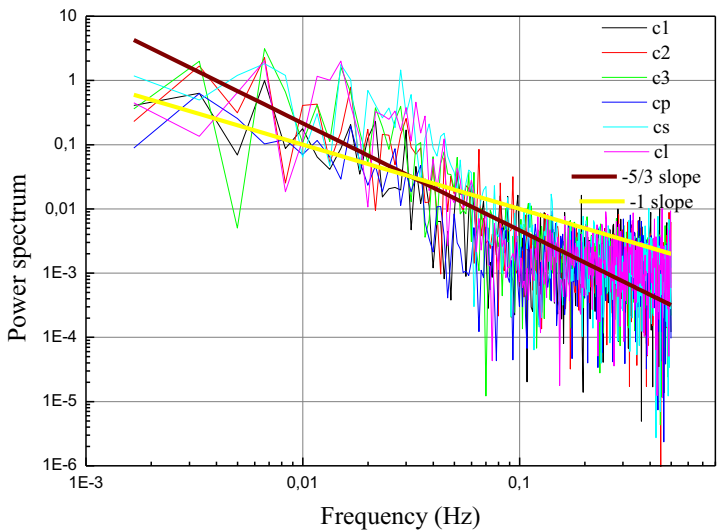

(f)

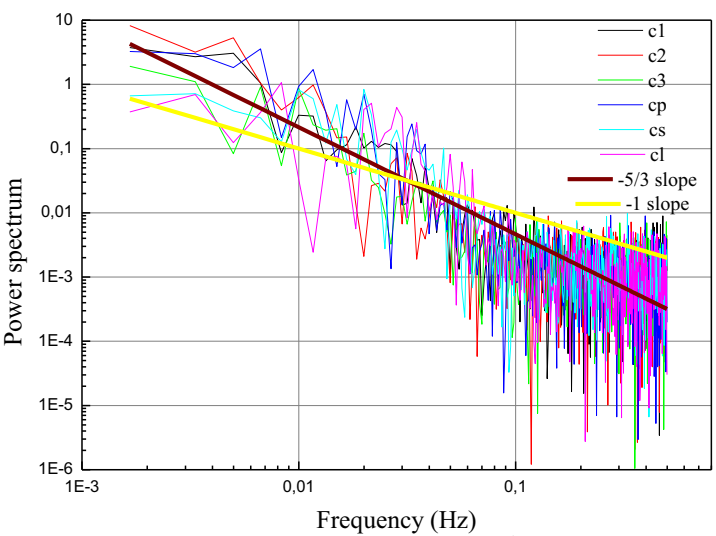

Figure 5. The power spectrum versus frequency for $\mathrm{Cu} 500$ (a) at $0[\mathrm{~T}]$ of magnetic induction, $\mathrm{Ra}_{\mathrm{TM}}=2.28 \cdot 10^{6}$, (b) $\log$-log scale at $0[\mathrm{~T}]$ of magnetic induction, $\mathrm{Ra}_{\mathrm{TM}}=2.28 \cdot 10^{6}$, (c) at $6[\mathrm{~T}]$ of magnetic induction, $\mathrm{Ra}_{\mathrm{TM}}=-2.38 \cdot 10^{8}$, (b) $\log$ - $\log$ scale at $6[\mathrm{~T}]$ of magnetic induction, $\mathrm{Ra}_{\mathrm{TM}}=-2.38 \cdot 10^{8}$, (c) at $8[\mathrm{~T}]$ of magnetic induction, $\mathrm{Ra}_{\mathrm{TM}}=-7.63 \cdot 10^{8}$, (b) $\log \log$ scale at 8 [T] of magnetic induction, $\mathrm{Ra}_{\mathrm{TM}}=-7.63 \cdot 10^{8}$.

In the left-hand side column (Figures 4(a), 4(c) and 4(e)) characteristic peak could be seen. As it was mentioned in Section 4.2, for the steady convective flow such peaks could represent vortical structure rotating with particular frequency. In all figures the frequency about $0.028[\mathrm{~Hz}]$ repeated oneself. It suggested one large vortex in whole volume of analyzed enclosure. The lower the frequency the larger should be the vertical structure. What is more important, this frequency was found for almost all thermocouples. Increasing magnetic induction from $0[\mathrm{~T}]$ to $8[\mathrm{~T}]$ caused decrease in the power spectrum, what corresponded with decreased values of the Nusselt number (Figure 3(a)). Both results indicated the suppression of convection.

The right-hand side column in Figure 4 (4(b), 4(d) and 4(f)) presents the power spectrum versus the frequency but in the log-log scale. The straight lines of $-5 / 3$ and -1 slopes were also marked. These slopes represented the inertial-convective and viscous-diffusive turbulent regimes, respectively. They did not fit the flat power spectrum distribution. The flat power spectrum distribution is characteristic for steady flow and confirmed the conclusion of attenuating influence of magnetic buoyancy force on the flow of $\mathrm{Cu} 50$. 
In Figure 5 the results of signal analysis for $\mathrm{Cu} 500$ are shown. The left-hand side column (Figures 5(a), 5(c) and $5(\mathrm{e})$ consists of the power spectrum distribution versus frequency, while the right hand side column (Figures 5(b), 5(d) and 5(f)) - of log-log scale representation of power spectrum. In Figures 5(a) and 5(b) the results were obtained at $0[\mathrm{~T}]$ of magnetic induction, in Figures 5 (c) and $5(\mathrm{~d})$ at $6[\mathrm{~T}]$ of magnetic induction and in Figures $5(\mathrm{e})$ and $5(\mathrm{f})$ at $8[\mathrm{~T}]$ of magnetic induction. Increasing magnetic field did not change much the distribution of power spectrum but in Figure 5(c) the most visible were two peaks, while in Figure 5(e) one. It looked like the magnetic field ordered slightly the flow. The power spectrum representation in log-log scale also confirmed different characteristic of $\mathrm{Cu} 500$ flow. The straight line of $-5 / 3$ slope was in good agreement with the power spectrum, what suggested the changes in flow were going towards the inertial-convective turbulent regime. The straight line of -1 slope did not fit the power spectrum distribution in any range.

\section{Summary}

In this paper the experimental analysis of thermomagnetic convection of low concentration nanofluids was presented. Two fluids of 50 [ppm] and 500 [ppm] copper particles concentration in the water were investigated. The influence of various magnetic induction values on the transport processes was checked. Estimation of the heat transfer and flow structure was able due to the signal analysis. The results discussion led to the following conclusions: (1) presented results did not show one clear tendency, what depended on the applied boundary conditions, (2) the heat transfer enhancement strongly depended on the position of experimental enclosure in the magnetic field, (3) analyzed position of experimental enclosure was characterized by the most complex force system from possible ones. It caused (a) increase of the Nusselt number at low magnetic induction values, up to 2 [T] for $\mathrm{Cu} 50$, (b) decrease of the Nusselt number at higher magnetic induction values, $<2$ [T] for $\mathrm{Cu} 50$, while increase for $\mathrm{Cu} 500$, (c) complex flow structure with local convection suppression, (4) reaction of the analyzed system on the magnetic field and additional magnetic buoyancy force is promising and shows its potential in the heat transfer enhancement area even with low concentration nanofluids.

\section{References}

1. A.M.L. Bethancourt, M. Hashiguchi, K. Kuwahara, J.M. Hyun, Int. J. Heat Mass Tran. 42 (1999)

2. X.Q. Wang, A.S. Mujumdar, Braz. J. Chem. Eng. 25 (2008)

3. E. Goharshadi, H. Ahmadzadeh, S. Samiee, M. Hadadian, Phys. Chem. Research 1 (2013)

4. X.Q. Wang, A.S. Mujumdar, Braz. J. Chem. Eng. 25 (2008)

5. R. Saidur, K. Leong, H. Mohammad, Renew. Sust. Energ. Rev. 15 (2011)
6. A. Sobti, R.K. Wanchoo, Mater. Sci. Forum, 757 (2013)

7. K. Khanafer, K. Vafai, M. Lightstone, Int. J. Heat Mass Tran. 46 (2003)

8. K.S. Hwang, J.H. Lee, S.P. Jang, Int. J. Heat Mass Tran. 50 (2007)

9. A.K. Santra, S. Sen, N. Chakraborty, Int.J. Therm. Sci. 47 (2008)

10. L. Schwab et al., J. Magn. Magn. Mater. 39 (1983)

11. T. Tagawa, R. Shigemitsu, H. Ozoe, Int. J. Heat Mass Tran. 45 (2002)

12. J. Huang, B. Edwards, Phys. Rev. E 57 (1998)

13. H. Ozoe, Magnetic Convection (Imperial College Press, 2005)

14. E. Fornalik, Magnetic convection of paramagnetic fluid in an enclosure (AGH Uczelniane Wydawnictwa Naukowo-Dydaktyczne, monograph, 2009)

15. K. Ezaki, M. Kaneda, T. Tagawa, H. Ozoe, ISIJ International 43 (2003)

16. T. Bednarz, E. Fornalik, T. Tagawa, H. Ozoe J.S. Szmyd, Int. J. Therm. Sci. 44 (2005)

17. P. Filar, E. Fornalik, T. Tagawa, H. Ozoe, J.S. Szmyd, J. Heat Transf. 128 (2006)

18. W. Wrobel, E. Fornalik-Wajs, J.S. Szmyd, Int. J. of Heat Fluid Fl. 31 (2010)

19. S. Kenjeres, L. Pyrda, E. Fornalik-Wajs, J.S. Szmyd, Flow Turbulence Combust. 92 (2014)

20. D.D. Ganji, A. Malvandi, Powder Technol. 263 (2014)

21. B. Ghasemi, S.M. Aminossadati, A. Raisi, Int. J. Therm. Sci. 50 (2011)

22. B. Ghasemi, Numer. Heat. Tr. A-appl, 63 (2013)

23. M. Sheikholeslami, M. Gorji-Bandpy, D.D. Ganji, S. Soleimani, IJST, Transactions of Mechanical Engineering 38 (2014)

24. D. Wu, H. Zhu, L. Wang, L. Liu, Curr. Nanosci. 5 (2009)

25. Y. Xuan, W. Roetzel, Int. J. Heat Mass Tran. 43 (2000)

26. J. Qi, N.I. Wakayama, A. Yabe, Int. J. Heat Mass Tran., 44 (2001)

27. H. Ozoe, S. W. Churchill AIChE Symposium Series, Heat Transfer 691973

28. J.W. Elsner, Turbulence of Flows (in Polish) (PWN, Warszawa, 1989)

29. W.D. McComb, The physics of fluid turbulence (Oxford University Press, Oxford, 1990)

30. http://www.fftw.org/

31. Superconducting Magnet Manual

\section{Acknowledgement}

The present work was supported by Polish National Science Centre Project No. 2012/07/B/ST8/03109. 